\title{
ATRAVESSAMENTOS NATURAIS NA PRODUÇÃO DE SUBJETIVIDADE AMBIENTAL
}

CRUCES NATURALES EM LA PRODUCCIÓN DE SUBJETIVIDAD AMBIENTAL

\section{NATURAL CROSSINGS IN THE PRODUCTION OF ENVIRNOMENTAL SUBJECTIVITY}

\author{
MAZZARINO, JANE \\ Doutora em Ciências da Comunicação, Univates, e-mail: janemazzarino@univates.br
}

\section{SCHEIBE, DENISE}

Mestranda em Ciências Médicas, Psicóloga, Univates, e-mail: denise.scheibe@universo.univates.br

\section{PETTER, BRUNO}

Graduando em Psicologia, Univates, e-mail: bruno.petter@universo.univates.br

\section{GRIEBELER, DEBORA}

Graduanda em Design, Univates, e-mail: debora.griebeler@univates.br

\begin{abstract}
RESUMO:
Uma escola pública, uma área verde, um grupo de alunos de 11 e 12 anos e um grupo de pesquisa que tinha como objetivo experienciar possibilidades de sensibilização ambiental baseadas em um método que explora atividades ao ar livre, visando à produção de uma subjetividade ambiental. Estes elementos foram geradores de encontros semanais que duraram três meses, optando-se por avaliar um processo de educação ambiental em continuidade, a fim de se estabelecer um vínculo com o grupo e observar com profundidade processos que os pesquisadores só investigavam em encontros esporádicos. A estratégia do grupo de pesquisa foi baseada no método do Aprendizado Sequencial de Joseph Cornell e na proposta ecosófica de Felix Guattari e suas três ecologias: subjetiva, social e ambiental. $\mathrm{O}$ objetivo foi investigar possibilidades de produção de subjetividade ambiental a partir da proposta ecosófica e de um método de educação ambiental ao ar livre. Como elemento conclusivo fundamental consideramos a evidência de que o contato coletivo com a natureza afeta as relações sociais, favorecendo a percepção do outro na sua singularidade. Ou seja, a natureza atua como facilitadora da abertura para o outro. A ecologia social e subjetiva ou mental, no caso em estudo, foram favorecidas pela ecologia do ambiente.
\end{abstract}

PALAVRAS-CHAVE: natureza; intervenções; ecosofia; subjetividade ambiental.

\section{RESUMEN:}

Un colegio público, una zona verde, un grupo de alumnos de 11 y 12 años y un grupo de investigación que tuvo como objetivo experimentar posibilidades de conciencia ambiental a partir de un método que explora actividades al aire libre, con el objetivo de producir una subjetividad ambiental. Estos elementos generaron reuniones semanales que duraron tres meses, optando por evaluar un proceso de educación ambiental continua, con el fin de establecer un vínculo con el grupo y observar en profundidad procesos que los investigadores solo investigaron en reuniones esporádicas. La estrategia del grupo de investigación se basó en el método de Aprendizaje Secuencial de Joseph Cornell y la propuesta ecosófica de Felix Guattari y sus tres ecologías: subjetiva, social y ambiental. El objetivo fue investigar las posibilidades de producción de subjetividad ambiental a partir de la propuesta ecosófica y un método de educación ambiental al aire libre. Como elemento concluyente fundamental, consideramos la evidencia de que el contacto colectivo con la naturaleza afecta las relaciones sociales, favoreciendo la percepción del otro en su singularidad. En otras palabras, la naturaleza actúa como facilitadora de la apertura al otro. La ecología social y subjetiva o mental, en el caso en estudio, fue favorecida por la ecología ambiental.

PALABRAS CLAVE: naturaleza; intervenciones; ecosofía; subjetividad ambiental.

\section{ABSTRACT:}

A public school, a green area, a group of students aged 11 and 12, and a research group that aimed to experience possibilities for environmental awareness based on a method that explores outdoor activities, aiming the production of an environmental subjectivity. These elements were generated from weekly meetings that lasted three months and we decided to evaluate them in the context of an environmental education process in continuity, to establish a link with the group, and observe indepth processes that researchers only investigated in sporadic meetings. The research group's strategy was based on Joseph Cornell's Sequential Learning method and Felix Guattari's ecosophical proposal and his three ecologies: subjective, social and environmental. The objective was to investigate possibilities for the production of environmental subjectivity from the ecosophical proposal and a method of outdoor environmental education. As a fundamental concluding element, we consider the evidence that collective contact with nature affects social relationships, favoring the perception of the other in their uniqueness. In other words, nature acts as a facilitator of opening to the other. Social and subjective or mental ecology, in the case under study, were favored by environmental ecology. KEYWORDS: nature; interventions; ecosophy; environmental subjectivity. 


\section{INTRODUÇÃO}

Experimentar trilhas desconhecidas solicita, dos caminhantes, disposição para desmontar, fragmentar, espichar, contornar e recompor o que lhes surge e, algumas vezes, estes verbos acabam sendo conjugados sobre si mesmos. Viver de uma maneira diferente é desafiante, pois requer que habitemos espaços desconhecidos e, muitas vezes, acompanhados de caminhantes outros, tão desconhecidos quanto o caminho, o que possibilita descobrir o espaço, o outro e, com isso, redescobrir a nós mesmos.

Os espaços a que nos referimos são de uma escola pública e de uma área verde; os caminhantes, um grupo de alunos de 11 e 12 anos com "dificuldades", conforme indicado pelas professoras, e um grupo de pesquisadores que tinha como objetivo experienciar possibilidades de sensibilização ambiental baseadas em um método que explora atividades ao ar livre, em um processo de educação ambiental com continuidade, que possibilitasse criar vínculos sociais e observar com profundidade. Ao longo de 10 semanas, os caminhantes encontraram-se nos espaços verdes de uma escola de Ensino Fundamental da rede pública de Lajeado, no Rio Grande do Sul, adentrando em grupo a área de mata ao lado da escola (Figura 1), para interagirem entre si e com a natureza, a fim de explorar a atenção por meio de atividades dirigidas. Na ocasião, eles tocaram e foram tocados pelo desconhecido, despertaram os sentidos que atravessam o corpo para além do tato: o olhar, os cheiros, os sabores, os sons e a intuição.

Figura 1- Área de atividades: mata ao lado da escola

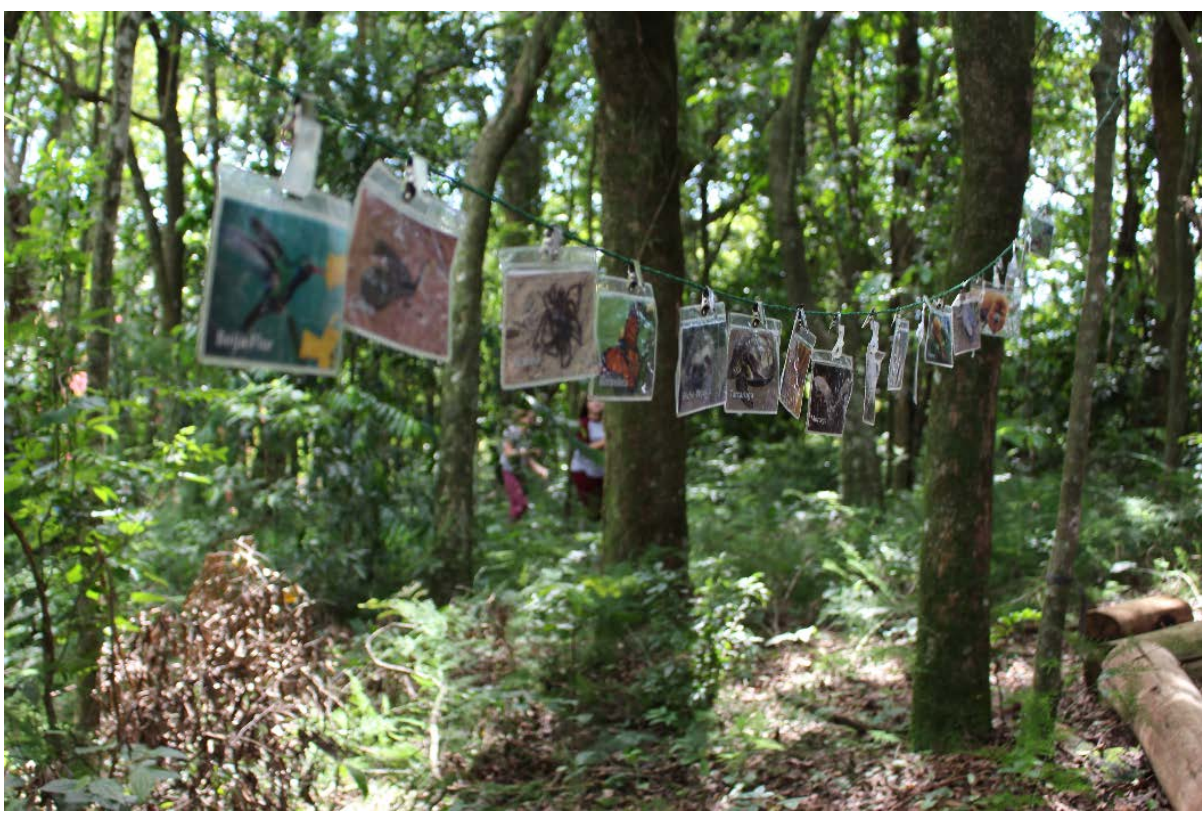

Fonte: Pietra Darde.

A esse respeito, enquanto pesquisadores, fomos movidos pela vontade de explorar um método de educação ambiental que fosse além dos encontros esporádicos, visando à investigação de uma possível produção de subjetividade ambiental, entendida como aquela que é produzida tanto por instâncias individuais, quanto coletivas e institucionais (GUATTARI, 2012). O método inspirador utilizado para provocar a subjetividade ambiental foi o Aprendizado Sequencial de Joseph Cornell $(2005,2008)$. Nesse sentido, observávamos como as crianças interagiam com e no ambiente natural em uma sequência de atividades, a fim de compreender, em um processo com continuidade e com o possível estabelecimento de vínculos, como se davam as interações. Também adentramos o campo atravessados pela teoria ecosófica de Guattari (1990), cuja perspectiva ocupa-se em fazer emergir novos territórios existenciais a partir da interconexão entre subjetividade, relações sociais e meio ambiente. Estes três registros ecológicos são movimentados na criação de territórios existenciais, tecidos a partir de linhas advindas da própria experiência vivida no aqui e no agora, como pelo acesso a experiências anteriores. Os territórios psicossociais são compostos por essas linhas, que podem ser observadas e mapeadas.

Entre as formas de registro das observações, consideramos adequado o relato cartográfico, que coloca o pesquisador como implicado pelo acontecimento da pesquisa e possibilita seu envolvimento intenso ao longo do mapeamento das linhas de força que emergem e compõem a experiência. Assim, tivemos como 
objetivo investigar as possibilidades de produção de subjetividade ambiental a partir da proposta ecosófica e de um método de educação ambiental ao ar livre. Consideramos, a priori, que os atravessamentos naturais são também produtores da subjetividade ambiental, de modo que a maneira como pode se dar esse acontecimento é o que nos instigou a investigar, sendo também o tema deste artigo.

\section{DESENVOLVIMENTO}

\section{Método do aprendizado sequencial}

As atividades de sensibilização ambiental foram pautadas pelo método do Aprendizado Sequencial de Cornell $(2005,2008)$, que organiza as atividades de educação ambiental de modo a fazer com que o sujeito entre gradativamente em sintonia com a natureza, valorizando-se mais a experiência que a fala. Além disso, o método é composto por 4 fases. Tudo começa com o Despertar do Entusiasmo, momento em que se utiliza a energia com que os participantes chegam na atividade para compor uma troca entre eles. Na etapa de Concentrar a Atenção, as atividades objetivam levar a uma condição tranquila. Já a terceira fase é a Experiência Direta, em que se busca fazer com que os participantes habitem o ambiente natural, explorando os sentidos, interagindo, experimentando-o de forma intensa e integral. A etapa final, por sua vez, é a de Compartilhar a Inspiração, quando cada participante relata ao grupo o que sentiu ao longo da experiência, o que o tocou, o que foi assustador, o que foi conhecido e percebido (CORNELL, 2008). Por ser um método muito flexível, ele se ajusta ao que emergir durante.

Segundo Mendonça (2000, p. 4), as atividades vivenciais são necessárias para o processo de construção da relação com a natureza e dão a conhecer sobre como cada processo acontece para cada um. "É o tipo da coisa que não se explica, não se ensina (....) É como a vida, que não pode ser aprendida sem a experiência".

\section{As oficinas}

A partir do método do Aprendizado Sequencial, formulamos um compilado de atividades que pudessem ser aplicadas na escola e que correspondessem à idade do grupo. Para cada semana, foram pensadas atividades conforme os objetivos das quatro fases, levando em conta o ritmo que o grupo apresentava e a aceitação daquilo que se apresentava a eles. As atividades caracterizaram-se por serem de sensibilização ambiental e possibilitarem potencializar a interação e a reflexão de maneira sensível e integral.

O grupo era formado por seis crianças com idade entre de 11 a 12 anos de idade, estudantes da mesma turma de uma escola municipal de Ensino Fundamental do Vale do Taquari, no Rio Grande do Sul. Era de interesse do grupo de pesquisa que o grupo de intervenção se mantivesse um contato contínuo e que a instituição de aplicação fosse próxima da Universidade, facilitando o deslocamento. Ao fazer contato com os gestores da escola, estes demonstraram interesse por atividades no turno inverso da aula para uma turma específica de sexto ano, por avaliar que a proposta poderia auxiliar com os problemas de relacionamento e/ou de aprendizagem que observavam. A escola intermediou o convite aos pais das crianças. Inscreveramse 2 meninos e 4 meninas.

Segundo a coordenadora pedagógica e a gestora da escola, na turma havia duas participantes que se negavam a participar de algumas aulas práticas. Um menino se caracterizava pelo traço de forte introversão, mesmo com a aproximação dos colegas, e outro desafiava os professores pela falta de atenção, demonstrando ansiedade e fazendo grande uso de palavrões, o que gerava exclusão pelos colegas. O garoto havia entrado na turma naquele ano e passava pela falta de acolhimento pelo grupo, apresentando dificuldades para se socializar.

Os encontros foram planejados levando em conta estas características do grupo. A periodicidade semanal foi definida por demanda da escola, a duração de duas horas para não serem cansativos. Os pesquisadores definiram a continuidade em uma série de 10 oficinas. Elas ocorreriam no bosque localizado ao lado da escola, onde havia uma diversidade ecológica e uma clareira com troncos deitados que formavam um círculo, bastante apropriado para a proposta do Aprendizado Sequencial. O planejamento foi criado com cada encontro tendo um tema central, que seria explorado através das quatro fases do método: Despertar o Entusiasmo, Concentrar a Atenção, Experiência Direta e Compartilhamento. As atividades (ilustradas pela Figura 2) são melhor exploradas nas análises. 


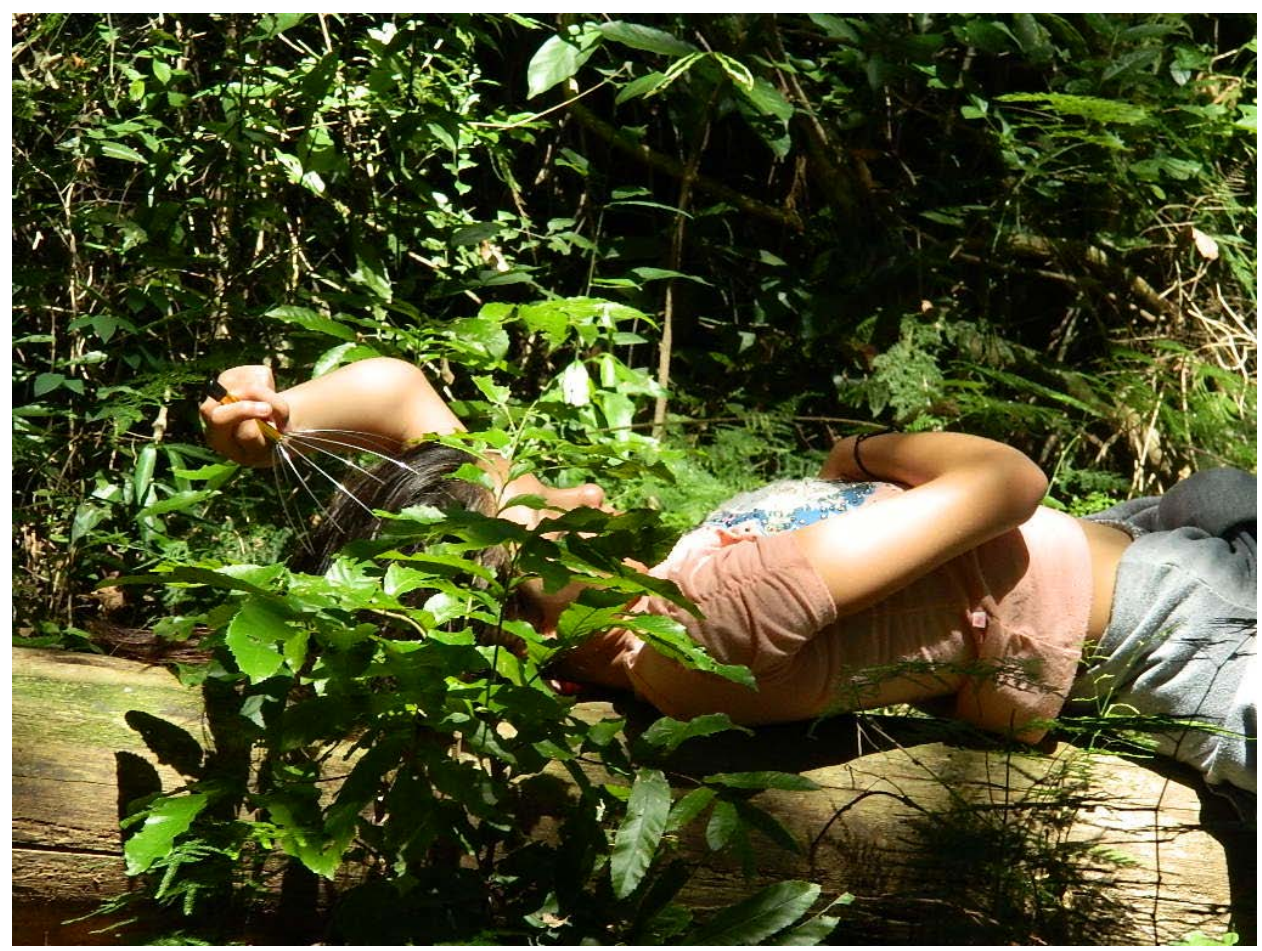

Fonte: Pietra Darde

Os temas dos encontros seguiram esta ordem: aproximar-se para a criação de vínculo inicial, conhecer o ambiente do bosque e descobrir o que é natureza para os participantes, apreciação da natureza em ambientes não naturais (escola e seus corredores), o sagrado na natureza, o nosso papel no cuidado ambiental com a exploração da natureza no bairro, aproximação e empatia com a natureza, atividades voltadas para um recurso natural (água), o eu na natureza: sou um elemento natural, por que tememos e/ou não gostamos de certos animais da natureza e como e porque destruímos a natureza, compartilhamento final com celebração. Este foi o último encontro com as crianças, quando sentamos em roda e conversamos sobre as experiências vividas, registrando graficamente, finalizando o processo com um divertido piquenique.

No planejamento foi definido que uma atividade perpassaria todos as oficinas: a Carteira de Identidade da Árvore, que os participantes escolheriam no bosque para, desde o primeiro encontro até o último, registrarem em diários de campo as mudanças observadas semanalmente. $\mathrm{O}$ objetivo dessa atividade foi servir de fio condutor da continuidade entre os encontros. Além da coordenadora do grupo, quatro bolsistas envolveram-se no projeto: um aplicando as atividades (função que a coordenadora assumiu também em alguns encontros), uma registrava, com uso de fotografia e audiovisuais, documentando as intervenções, outros dois registravam por meio de relatos cartográficos escritos. Kastrup e Passos (2013, p. 267) ensinam que "a pesquisa cartográfica busca acessar um plano comum (...)", uma composição que se mostra a partir das singularidades e se expõe como uma coletividade, um "protagonismo de todos". Dessa maneira, todos foram incluídos como agentes de transformações e de mudanças: pesquisadores e crianças.

A cartografia é um modo de habitar e registrar os acontecimentos que emergem ao longo das atividades. "Cartografamos com afetos, abrindo nossa atenção e nossa sensibilidade a diversos e imprevisíveis atravessamentos" (KASTRUP; PASSOS, 2013, p. 277). Nesse viés, o investigador cartógrafo habita o espaço criado para e pela pesquisa, olha para cada movimento que vai sendo composto, integra-se à história e abraça cada sensação, pois é com o acontecimento que ele opera. Segundo Barros e Silva (2013), o cartógrafo está aberto ao inusitado, aos atravessamentos múltiplos pelos quais a pesquisa é tomada, os quais se agenciam e se interconectam, demandando escolhas, decisões. Na experiência realizada, além dos relatos cartográficos, foram coletados registros por meio de fotografias, de filmagens e de gravações de voz. 


\title{
3 Produção de subjetividade ambiental nas experiências ecosóficas com as crianças
}

Ao estudar a sociabilidade que é decorrente da interação com os meios naturais, objetiva-se um olhar para como acontecem as relações dos sujeitos com esse lugar. Sabe-se que a relação com a natureza desperta os mais diversos signos e, muitas vezes, desperta devires.

\begin{abstract}
O devir não designa um estado de insuficiência. Não é uma falta de ser. Ele não carece vira-ser outro para tornar-se real. Nem por imitação (copiar outro), nem por identificação (ser outro), tampouco por transposição de relação (fazer como outro). Devir é tornar-se diferente de si. É potência de acontecer, diferindo de si sem jamais confundir-se com o estado resultante dessa mudança. O devir é potência de mudar [...] Devir é visitar e ser visitado por intensidades que brotam e se fabricam nos limiares ou nas zonas de passagem, por variações que se insinuam nos interstícios das formas, por insistência e pressão de um real apenas virtual, mas que por isso mesmo faz variar a própria natureza da diferença. [...] Devir: potência em ato; desejo sempre preenchido pelo ato imanente àquilo que acontece (FUGANTI, 2020, on-line).
\end{abstract}

Devires nos tomam, também, pelo encontro de linhas de um e outro, uma vez que todas as nossas relações são compostas por linhas que podem ser duras, moles, moleculares (DELEUZE; GUATTARI, 2011), as quais compõem e moldam a nossa subjetividade, desestratificam as nossas relações conosco mesmos e com o meio, seja ele social ou natural. Quando se parte de uma subjetividade que vem sendo moldada e composta ao longo da vida por um olhar que não é decorrente da natureza, é possível acessar uma subjetividade que está enraizada em saberes não ambientais. Contudo, quando estimulamos esse olhar incluindo a vida não humana, produzimos uma subjetividade ambiental. Para Mendonça (2012, p. 95), "o contato direto com a natureza é o que permite à mente humana desenvolver ideias a partir da fonte original que deu origem à possibilidade de pensar".

A subjetividade, por si só, é composta por vivências pessoais e coletivas que estão em condição de emergir enquanto "território existencial/autorreferencial" (GUATTARI, 2012, p. 19). Sendo assim, as trocas feitas ao longo da nossa existência são responsáveis pelas nossas escolhas e afetações, de modo que em cada composição na qual haja uma afetação, é possível que emerja uma nova linha ou que se modifiquem as que já existem e, a partir disso, componham-se outras mais e assim por diante. Enquanto produção de subjetividade ambiental, podemos pensar em uma produção que acontece por meio das relações construídas através e pelo meio ambiente. Isso é, em um processo decorrente de sensibilização ambiental, em que os sujeitos afetados pelo processo de educação ambiental inscrevem, em sua maneira de ser com a sociedade, com o meio ambiente e consigo mesmos, um olhar que insere a percepção de sua importância enquanto sujeito ecológico.

"Não existe separação entre eu e o mundo. Existe um contato permanente, quer percebamos quer não", diz Mendonça (2000, p. 4). Ou seja, esse contato nos atravessa a todo instante e, quando somos estimulados a pensar e viver uma experiência que o reforça, fortalecemos esse âmbito que, por vezes, tem se perdido. Guattari (2012) pontua que nossa subjetividade é alterada, conforme nossas relações sociais. O autor defende que muito do que somos é resultado da nossa configuração familiar e de crenças defendidas por ela. Para o autor:

[...] em certos contextos sociais e semiológicos, a subjetividade se individua: uma pessoa, tida como responsável por si mesma, se posiciona em meio a relações de alteridade regidas por usos familiares, costumes locais, leis jurídicas... Em outras condições, a subjetividade se faz coletiva, o que não significa que ela se torne por isso exclusivamente social. Com efeito, o termo "coletivo" deve ser entendido aqui no sentido de uma multiplicidade que se desenvolve para além do indivíduo, junto ao socius, assim como aquém da pessoa, junto a intensidades pré-verbais, derivando de uma lógica dos afetos mais do que de uma lógica de conjuntos bem circunscritos (GUATTARI, 2012, p. 19).

Pensar a produção de subjetividade ambiental a partir das experiências provocadas em oficinas de sensibilização ambiental ao ar livre, nas quais interagiram crianças e pesquisadores, movimentou diferentes categorias relacionadas à subjetividade ambiental. Dentre elas, podemos considerar: (i) as relações que as crianças tiveram entre si antes ao chegarem no local para realizar as atividades; (ii) a maneira com que já se relacionavam com o ambiente natural; (iii) a relação que passaram a construir com o ambiente e com os pesquisadores a partir das oficinas semanais; (iv) os efeitos produzidos pelas afetações que emergiram.

Todas essas categorias configuram parte do processo de produção de subjetividade ambiental, que já se formavam ao longo das vidas dos/das participantes e que, através das práticas de sensibilização, se intensificaram ou se modificaram. Essas "instâncias humanas intersubjetivas", como denomina Guattari 
(2012, p. 19-20), foram "manifestadas pela linguagem e instâncias sugestivas ou identificatórias", constituindo material para os relatos cartográficos.

\section{Emergências cartográficas}

Crianças e natureza movimentam-se no espaço verde, intensidades e velocidades de ambos se cruzam, gerando agenciamentos mútuos e criando um devir-criança-natureza. Assim, a proximidade das crianças com a natureza foi sendo percebida quando emergiam o devir criança-mato ou o devir criança-animal. A escolha por um animal que gostariam de ser expôs fantasias em relação a si mesmos, elementos mágicos e naturais, e as concepções que elas têm da natureza.

Elas não incluem o ser humano como parte da natureza, mas as plantas e os animais sim, sendo que apenas quando fazem o mapa dos sons, incluem sons humanos. Em seu plano comum emergente das interações junto à natureza, no presente, percebem-na no processo de nominá-la: mágica; linda; vida; silêncio e som; paz e luz; finita; verde; feita de montanhas; de vale; ar puro; barulho; tudo de bom; floresta; cantos; venenos. Diferente do presente, no futuro imaginam que não haverá natureza, e sim prédios, fábricas, casas, extinção, poluição e desmatamento. Para eles, quem cuida da natureza é Deus, índio ou cachorro, porém eles mesmos não se incluem nessa pequena lista. Em um dos últimos encontros, quando questionadas sobre quem cuida dos rios, que consideram que está sujo, as crianças dizem que são as pessoas, e nesse momento percebe-se que algo mudou.

Em alguns momentos elas reproduzem a lógica da sala de aula, olhando a pesquisadora-mediadora como professora e competindo pela sua atenção. Quando são convidadas a explorar o ambiente natural, empolgam-se, demonstram curiosidade, divertem-se, compartilham achados, desenhos e outras linguagens (Figura 3), e lanches. Escolhem as coletas na natureza por beleza ou por se identificarem: "gosto", "é bonito", e destacam as sensações durante as atividades.

Figura 3 - Atividade de criação de um lugar com uso de argila

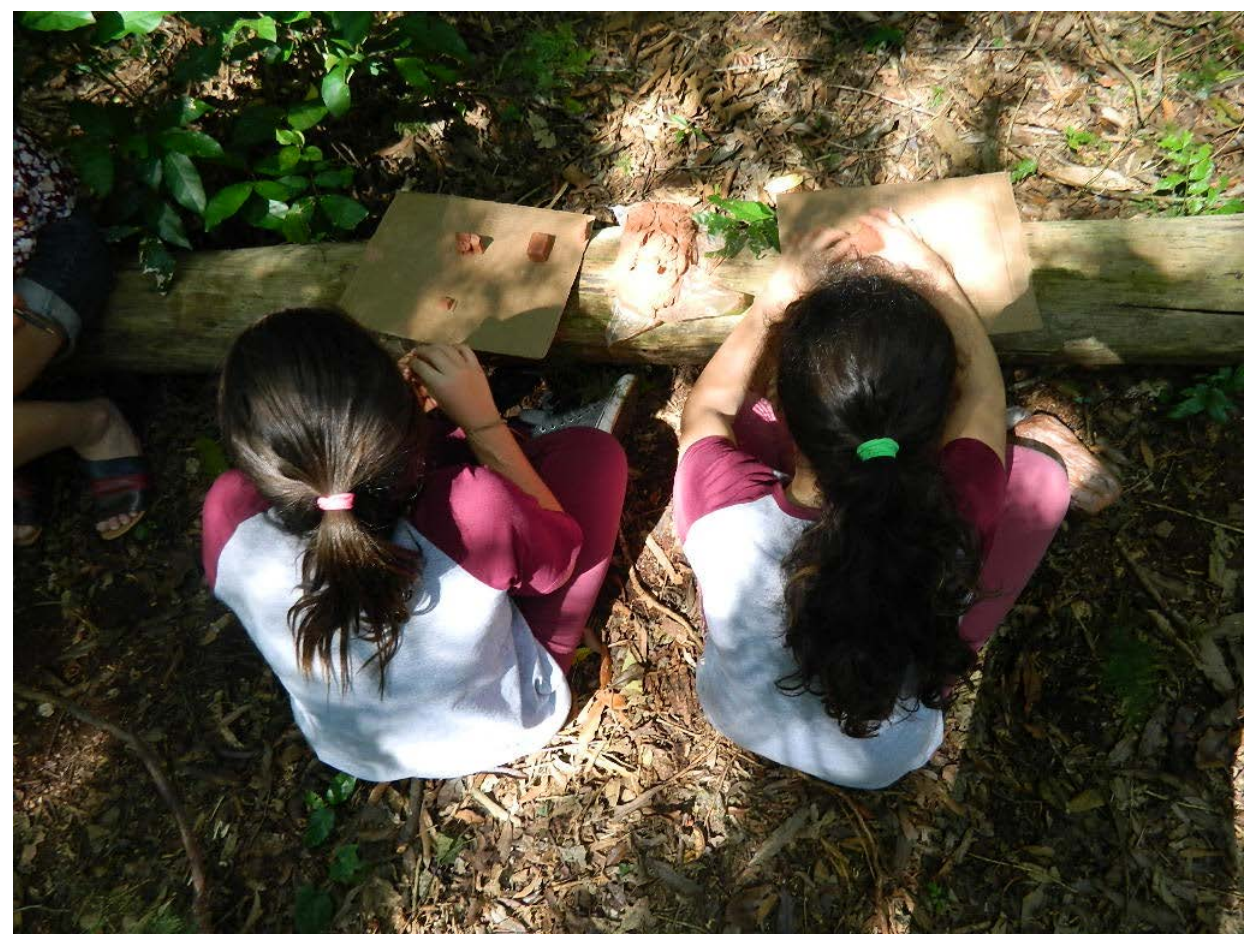

Fonte: Pietra Darde

Todas as semanas, eles têm um momento com sua árvore, em que percebem sua transformação, que está descascando, com menos bichos e folhas que na semana anterior, com mais brotos. Informam que coisas estão nascendo; tem rugas e cascas, musgos; folhas crescem e há uma planta num buraco que também se desenvolveu; há calombos, teia de aranha e cipós; criou raízes, galhos e buracos, cresceu. Eles imaginam coisas vivendo dentro da árvore, talvez algum bicho. Quando estão mais agitados não percebem diferenças 
nas suas árvores e, ao longo dos encontros, vão se desinteressando por essa atividade, talvez por ser a única repetitiva.

Quando de olhos vendados, ficam curiosos e demonstram algum incômodo e estranhamento, o que afeta sua entrega à atividade. Convidados a olhar à sua volta com a lupa, surpreendem-se: "porque isso é assim?" A lupa instiga o devir-investigador. "Vou ser um detetive", diz um deles. O exercício empolga quando descobrem as texturas de um cogumelo, que o menino cheio de intensidades quebra, deixando os colegas chateados.

A lupa deixa ver melhor, aproxima a criança da natureza. Com esse objeto elas adentram um universo mágico, detalham o olhar, estranham o que era conhecido por um olhar anterior pouco atento. $E$, além de explorarem a visão micro da natureza, também observam uns aos outros: aproximam a lupa do olho do colega, do cabelo, de si mesmos.

Querem sempre caminhar pelas trilhas e observar os animais. Empolgam-se, andam e organizam-se naturalmente em grupos para explorar a natureza, pois gostam de aventurar-se pela mata. Nas atividades escritas, entregam-se com menor intensidade, já que gostam mesmo é de uma boa conversa, o que aponta para a necessidade de escritas curtas com crianças. Quando se "atropelavam" no uso da palavra, o "bastão da fala" organizava as manifestações. Já a presença de um gravador de voz, usado para registro dos pesquisadores, intimidou-os: falavam mais baixo, demonstravam ficar um pouco desconfortáveis.

O corpo está pleno de energia, querem atividades motoras e sensórias. Quando as atividades os seduzem, sequer querem fazer intervalos. Exploram o espaço e são rápidos com brincadeiras e jogos de adivinhações sobre temas ambientais, que promovem concentração e os mantém participativos.

Na proposta de criar usando tintas feitas de pigmentos naturais (Figura 4), se percebem sem pincéis e são desafiados a criá-los a partir de coisas da natureza. Situações desafiantes os deixam empolgados. Os pincéis surgem feitos com fibras de taquaras. Inventam.

Figura 4 - Atividade com pigmentos naturais

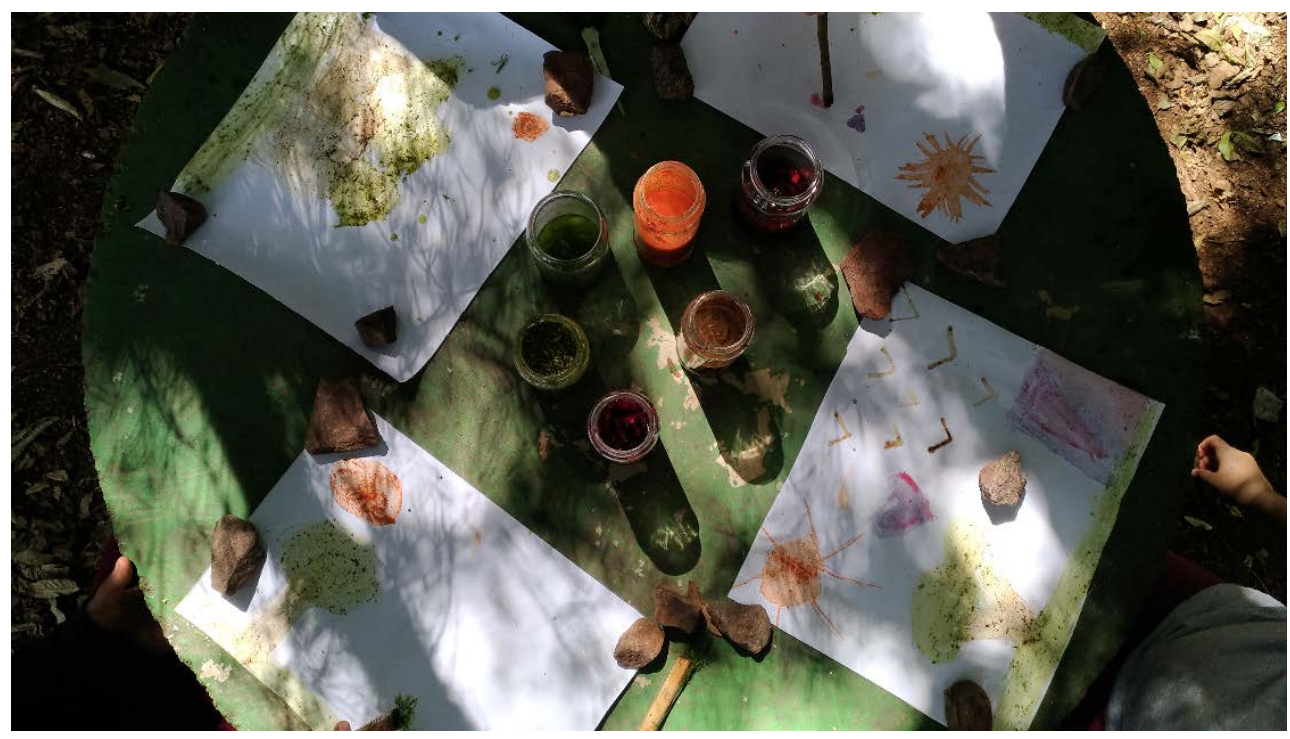

Fonte: Pietra Darde

O uso da máquina fotográfica também os empolgou e, com as fotografias, criaram fotolivros e inventaram histórias a partir das imagens coletadas em caminhadas. Eles gostam de explorar o celular, de Netflix e do YouTube. Demonstraram, ainda, em alguns momentos em que citaram passagens de programas e filmes, ter sua imagem de natureza mediada midiaticamente. Também nos relatos das professoras, elas apontaram que as tecnologias de mídia são objetos de interesse deles, o que nos fez ver a potência de explorar mais esses elementos nas oficinas de educação ambiental. 


\section{Composições, linhas e subjetividades ambientais}

Ao experienciarem atividades ambientais, os sujeitos, por meio da afetação ou da não afetação, passaram a construir e modificaram linhas estruturantes da sua subjetividade. $O$ ser humano foi incluído como responsável pela natureza, junto com Deus, os índios e os animais. As atividades, nesse sentido, podem ser caracterizadas como propulsoras dessa transformação coletiva e, portanto, de acesso a um plano comum, que poderá ou não ser alterado, a fim de compor outras estruturas no decorrer da vida.

Os relatos cartográficos informam que o grupo de crianças apresentou, inicialmente, uma relação utópica com a natureza, pensando nela como uma entidade mística. A essa relação acoplava-se outra, catastrófica, expressa quando um dos participantes afirmou que "não haverá natureza no futuro", projetando este tempo como um lugar sem recursos naturais, ao passo que uma menina disse que a natureza vai existir, mas com "mais extinção, desmatamento e poluição". Na construção das subjetividades ambientais, as crianças capturam energias de desesperança que assolam o mundo.

Essas manifestações da linguagem carregam marcas identificatórias de um discurso que circula socialmente: se o espaço natural não for cuidado, ele não sobreviverá. Em alguns momentos emergiu a ideia de que, para eles, não existe nada que possa ser feito para resgatar a natureza desse destino, ou seja, a percepção de uma natureza que já não tem solução é provocada pelas construções que se somaram até os nossos encontros, visto que o grupo demonstrava um olhar já constituído daquilo que havia vivenciado até então.

As crianças se identificavam com o belo no ambiente natural. Na descrição sobre a maneira com que se reconhecem em "suas árvores", foi possível perceber uma linguagem embrenhada de delicadeza e de aceitação. Nesse sentido, um dos alunos elegeu para si uma árvore que, como explicitou, se assemelhava "ao seu jeito de ser".

A relação com os animais também foi mencionada. Além do cão como um dos protetores da natureza, esse animal também apareceu como sendo um amigo, pois cuida da casa. Animais desconhecidos ou com aparência que os desagradasse causavam repulsa a quase todos do grupo. Esse julgamento atrelava-se às linhas que já haviam sido compostas antes das atividades e que compunham a subjetividade ambiental, conforme experienciada pelo grupo.

Ao longo das oficinas, a relação das crianças com a natureza foi sendo perpassada pelo senso de responsabilização. Do olhar utópico e catastrófico, foram migrando para um discurso sobre a responsabilidade das pessoas pelo que acontece na natureza. Desse modo, percebemos que a trajetória histórica da relação dos humanos com e na natureza foi revivida pelo grupo de crianças ao longo das experiências criadas por meio das oficinas (Figura 5).

Figura 5 - Atividade sobre transformação

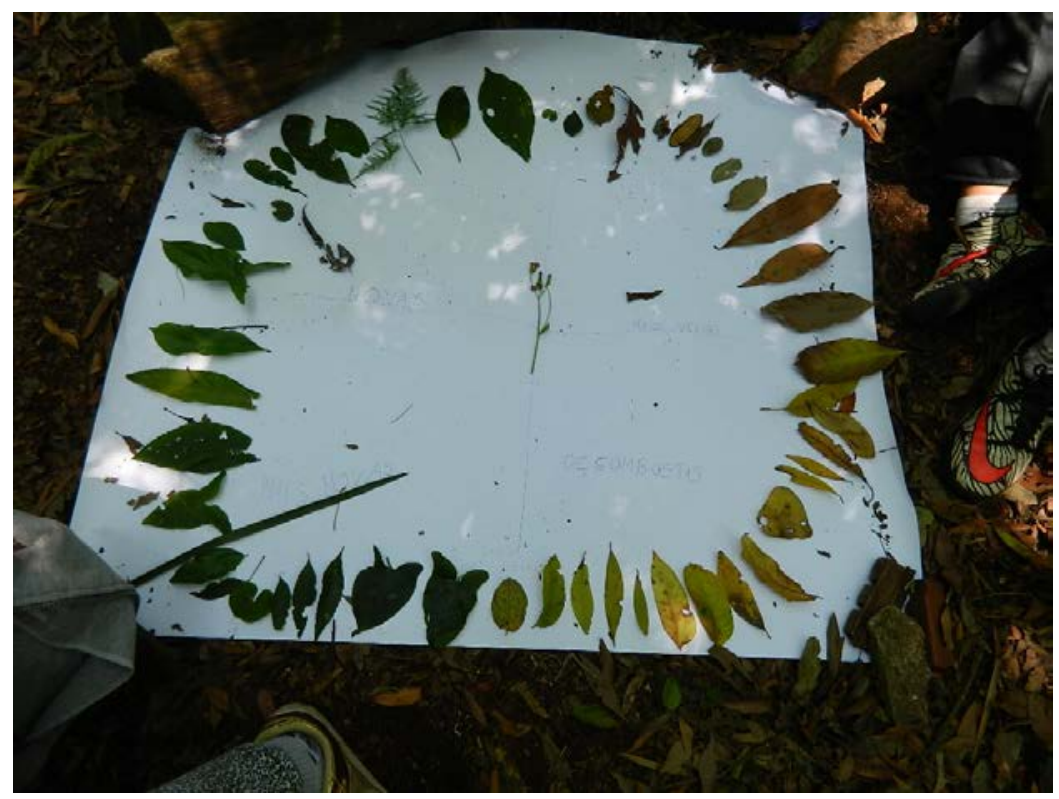

Fonte: Pietra Darde 
Apesar de não associar à noção de conservação, eles concebiam que o espaço natural precisa ser cuidado, pois previram o que acontecerá se não for cuidado. As crianças também consideraram que havia algo que zelava por esse espaço e, apesar de, inicialmente, não reconhecerem a si mesmos como agentes desse cuidado, reconheceram a necessidade de algum humano responsabilizar-se por isso, de modo que a noção de responsabilidade pelo cuidado desse outro-natureza passou a fazer parte da linguagem do grupo. Desse modo, as linhas de experiência, provocadas com a intervenção dos pesquisadores, teceram-se junto à subjetividade ambiental construída em um tempo-espaço anterior às oficinas, compondo um olhar que já não era mais o mesmo.

O fato de o grupo de crianças ter sido enquadrado, inicialmente, como com "dificuldades", não foi limitador para as atividades. Ao contrário, as possíveis "dificuldades" acabaram mostrando a potência do método. O que se observou foi a não aceitação de um dos meninos por parte do grupo sendo modificada ao longo do processo de sensibilização, evidenciando que as relações em meio à natureza afetam as relações sociais, provocando a naturalização das diferenças em relação ao outro, ou seja, o ambiente natural favorece a alteridade, conclusão que só foi possível devido à continuidade do processo por um período de três meses. As investigações anteriores, baseadas no mesmo método, mas com intervenções esporádicas e com grupos diferentes, não possibilitavam essa observação longitudinal.

Buscamos não conhecer, antes das intervenções, o perfil dos alunos traçados pelas professoras, para estarmos abertos, sem o risco de rotulá-los. Após o término das atividades vivenciais na natureza, os pesquisadores reuniram-se com as professoras para conversar sobre o grupo que participou até o final dos encontros e para finalizar o processo de intervenção. Os relatos das professoras apontaram para transformações observadas, sobre as quais não podemos afirmar que decorreram somente das oficinas, mas sim levantar hipóteses sobre essa possibilidade. Um dos meninos apresentou melhora no "relacionamento" e esteve mais "participativo". O outro também estava mais participativo e sociável. Uma das meninas esteve mais "interativa", enquanto outra também interagiu mais e demonstrou ter "menos vergonha" na apresentação de trabalhos. A terceira menina avançou em relação às dificuldades que apresentava, mostrando-se mais comprometida, respeitando mais as opiniões alheias, mais concentrada e organizada, e apresentando maior envolvimento em jogos. A outra menina tornou-se mais responsável, mais comprometida, mais autônoma e mais segura, expondo-se quando necessário e até "falando mais alto agora". Como se pode ver, as observações das professoras apontam para afetações sobre aspectos relativos à participação, relacionamento e autonomia.

Outro elemento a ser levado em conta é que a singularidade do espaço físico de cada escola gera resultados diferentes mesmo com métodos semelhantes sendo aplicados. A escola em que realizamos o estudo apresentava uma estrutura de mata bastante rica, o que devemos levar em consideração para os resultados. O espaço natural comunitário preservado está ao lado da escola e à disposição dela, o que não é comum. Este e os outros elementos compuseram a experiência relatada, sintetizada na imagem da Figura 6 como ações despertadas.

Figura 6 - Ações despertadas nas experiências 
Assim, as singularidades que as linhas assumem em cada contexto socioambiental afetam e são afetadas pelas intervenções e experiências que vão ser provocadas nesses mesmos espaços. As ações despertadas por meio das intervenções (Figura 1, 2, 3, 4, 5) se fazem linhas que cruzam e transmutam-se. Essas linhas são produtoras de composições rizomáticas (DELEUZE; GUATTARI, 2011) e têm padrões diferenciados, conforme o que invade os processos de educação ambiental e o design que se dá às intervenções. Cada composição é feita de uma linha interligada a outra que, provavelmente, começou em uma outra e assim por diante, nunca parando de se inter-relacionar e reconfigurando continuamente territórios existenciais a partir das relações sociais, subjetivas e ambientais. Dessa forma, a proposta ecosófica de Guattari (1990) retoma a noção de que somos seres interdependentes, conectados por meio dessas três dimensões ecológicas.

O autor pontua que as relações humanas, sociais e ambientais tendem a se deteriorar e deposita a responsabilidade sobre essa deterioração na maneira com que o socius tem deixado de lado as outras duas dimensões. A experiência gerada com as crianças provocou a retomada dessas dimensões quando recompôs relações sociais e naturais. Portanto, por meio dessas novas relações, podemos criar com intervenções sensibilizadoras e reterritorializar subjetividades.

Ao propor um olhar filosófico ao estado de inércia no qual se vive, a ecosofia propõe também um exercício de reflexão sobre como se vive. A continuidade das oficinas ambientais com as crianças possibilitaria, além de observar como elas se relacionam com os outros e com o espaço natural, compreender como elas compõem linhas da subjetividade ambiental com o espaço da comunidade escolar, do bairro, da família e outros.

\section{CONSIDERAÇÕES FINAIS}

Como elemento conclusivo fundamental consideramos a evidência de que o contato coletivo com a natureza afeta as relações sociais, favorecendo a percepção do outro na sua singularidade. Ou seja, a natureza atua como facilitadora da abertura para o outro. A ecologia social e subjetiva ou mental, no caso em estudo, foram favorecidas pela ecologia do ambiente. Para Guattari (1990), a "ecosofia social" refere-se a práticas desenvolvidas que modificam o olhar do ser em espaços de troca com o outro, de sociabilidade. Por sua vez, a "ecosofia mental" busca realizar trocas para reinvenção da relação do sujeito consigo mesmo. "A questão da ecologia mental pode surgir em todos os lugares, para além dos conjuntos bem constituídos na ordem individual ou coletiva" (GUATTARI, 1990, p. 39). Já a relação do ser-humano com a natureza, está engendrada de forma transversal em todos os esquemas da vida do sujeito, pois a natureza deve ser pensada em todas as relações, não se limitando a ser pauta de determinados grupos.

Assim, Guattari (1990) propõe pensar em uma composição humana que não esquece que é parte integrante da natureza, de modo que as ações de cada um e de todos provocam transformações naturais. O fato é que somos natureza e não há nada que não seja e, nesse sentido, as três dimensões ecológicas agem e retroagem como vasos comunicantes, gerando mudanças uma na outra e afetando a produção da subjetividade ambiental. Dessa forma, as mudanças decorrentes dessa retroalimentação transmutam a nossa forma de agir e interagir com nossa própria configuração de subjetividade ambiental.

Finalmente, entendemos como relevante mencionar que, a partir de intervenções inspiradas na ecosofia e do aprofundamento teórico em relação aos aspectos da comunicação, da educação e do ambiente, criou-se uma proposta metodológica que explora técnicas relacionadas à ampliação do contato com a natureza, a expressão por meio das artes e as tecnologias sociais e midiáticas (MAZZZARINO, 2021)., a qual denominase Ecosofia NAT (Natureza, Arte, Tecnologia), que sintetiza três dimensões de uma proposta de design para comunicação ambiental.

\section{AGRADECIMENTOS}

Os autores agradecem ao Conselho Nacional de Desenvolvimento Científico e Tecnológico - CNPq e à Universidade do Vale do Taquari - Univates pelo apoio. E, em especial, a Prietra Darde, pelos registros fotográficos.

\section{REFERÊNCIAS}

BARROS, M. E. B; SILVA, F. H. O trabalho do cartógrafo do ponto de vista da atividade. Fractal: Revista de Psicologia, Rio de Janeiro, v. 25, n. 2, p. 339-355, mai/ago 2013. Disponível em: 
<http://www.scielo.br/scielo.php?script=sci_arttext\&pid=S1984-02922013000200008\&lng=en\&nrm=iso>. Acesso em 21 de julho de 2020.

CORNELL, J. Vivências com a Natureza 1. São Paulo: Editora Aquariana, 2005.

CORNELL, J. Vivências com a Natureza 2. São Paulo: Editora Aquariana, 2008.

DELEUZE. G; GUATTARI, F. Mil Platôs. Rio de Janeiro: Editora 34, 2011.

FUGANTI, L. Devir. In: GALLI, T. M.; NASCIMENTO, M. L.; MARASCHIN, C. Pesquisar na diferença: um abecedário. Porto Alegre: Sulina. pp. 73-77, 2012.

GUATTARI, F. As três ecologias. Campinas: Papirus, 1990.

GUATTARI, F. Caosmose: um novo paradigma estético. São Paulo: Editora 34, 2012.

KASTRUP, V; PASSOS, E. Cartografar é traçar um plano comum. Fractal: Revista de Psicologia, Rio de Janeiro, v. 25, n. 2, p. 263-280, mai/ago. 2013. Disponível em: <http://www.scielo.br/scielo.php?script=sci_arttext\&pid=S198402922013000200004\&lng=en\&nrm=iso>. Acesso em 21 de julho de 2020.

KOTULAK, M.; ZUBOWICZ, G.; TRACEY I, G. (Eds.). Games for Nature: Environmental Education Through the Eyes of Young People. Youth and Environment Europe, 2010. Disponível em: https://yeenet.eu/archives/images/stories/pdf_books/GAMES_FOR_NATURE.pdf Acesso em: 21 de julho de 2020.

MAZZARINO, J. M. Ecosofia NAT: design para comunicação ambiental. Iguatu, CE: Quipá Editora, 2021. Disponível em: https://quipaeditora.com.br/ecosofia-nat Acesso em: 6 de dezembro de 2021.

MENDONÇA, R. A experiência na natureza segundo Joseph Cornel. In: SERRANO, C. A educação pelas pedras ecoturismo e educação ambiental. São Paulo: Editora Chronos, pp. 135-154, 2000.

MENDONÇA, R. Meio ambiente \& Natureza. São Paulo: Editora Senac, 2012.

NOTA DO EDITOR $\left(^{*}\right)$ : O conteúdo do artigo e as imagens nele publicadas são de responsabilidade do(s) autor(es). 